\title{
Young Stroke Mortality in Fiji Islands: An Economic Analysis of National Human Capital Resource Loss
}

\author{
Jagdish C. Maharaj ${ }^{1}$ and Mahendra Reddy ${ }^{2}$ \\ ${ }^{1}$ Lourdes Hospital and Community Health Service, P.O. Box 974, Dubbo, NSW 2830, Australia \\ ${ }^{2}$ College of Business, Hospitality and Tourism Studies, Fiji National University, P.O. Box 7222, Nasinu, Fiji
}

Correspondence should be addressed to Jagdish C. Maharaj, jmaharaj@chcs.com.au

Received 3 February 2012; Accepted 2 March 2012

Academic Editors: B. Drukarch, R. L. Macdonald, and A. K. Petridis

Copyright ( 2012 J. C. Maharaj and M. Reddy. This is an open access article distributed under the Creative Commons Attribution License, which permits unrestricted use, distribution, and reproduction in any medium, provided the original work is properly cited.

\begin{abstract}
Introduction. The objective of this study was to perform an economic analysis in terms of annual national human capital resource loss from young stroke mortality in Fiji. The official retirement age is 55 years in Fiji. Method. Stroke mortality data, for workingage group 15-55 years, obtained from the Ministry of Health and per capita national income figure for the same year was utilised to calculate the total output loss for the economy. The formula of output loss from the economy was used. Results. There were 273 stroke deaths of which $53.8 \%$ were of working-age group. The annual national human capital loss from stroke mortality for Fiji for the year was calculated to be F\$8.85 million (US\$5.31 million). The highest percentage loss from stroke mortality was from persons in their forties; that is, they still had more then 10 years to retirement. Discussion. This loss equates to one percent of national government revenue and $9.7 \%$ of Ministry of Health budget for the same year. The annual national human capital loss from stroke mortality is an important dimension in the overall economic equation of total economic burden of stroke. Conclusion. This study demonstrates a high economic burden for Fiji from stroke mortality of young adults in terms of annual national human capital loss.
\end{abstract}

\section{Introduction}

"Stroke is a cause of poverty and is caused by poverty” [1].

The epidemiological changes through advances in socioeconomic developments and changing demographics have altered the profile of the major causes of mortality and morbidity. Fiji is undergoing transition as is occurring in most other developing regions of the world. Rapid urbanization and globalisation have brought changes in life styles that have produced a surge in mortality and morbidity noncommunicable diseases (NCDs) such as cancer, cardiovascular diseases including stroke and ischaemic heart disease, chronic obstructive pulmonary diseases, and mental disorders. NCDs account for $62 \%$ of all deaths and $50 \%$ of the disability burden in the Economic and Social Commission for Asia and the Pacific region [2] and are at the point of a global crisis [3]. Several reports in the literature implicate stroke as the third leading cause of death and an important cause of hospital admission and long-term disability [4-6]. Over the decades some decline in stroke mortality has also been reported [7-9].

Stroke incidence ranges between 7 and 15 per 100,000 people/year [10] to 8.63 to 19.12 per 100,000 people/year [11] with substantial global variation in the relative burden of stroke [12]. Increasing burden of stroke, particularly in low-to-middle income countries like Fiji has been reported. Feigin et al. in a review showed a divergent, statistically significant trend in stroke incidence rates over the past four decades, with a $42 \%$ decrease in stroke incidence in highincome countries and a greater than $100 \%$ increase in stroke incidence in low-to-middle income countries [13]. The World Health Organisation (WHO) in its NCD Surveillance: STEPwise approach to stroke surveillance estimated that in 2002 strokes resulted in 5.5 million deaths worldwide, making it the leading cause of death, and the projections to the year 2020 indicate that the number of people suffering from stroke each year will substantially increase, the majority 
of the disease burden being in the low-to-middle income countries [14]. Stroke in young not only poses different set of challenges for the individual, family, and society requiring different approach to investigation and management [10] due to differing etiological nature compared to the aged population, but the affection of economically productive person in prime of their life, particularly in developing countries, adds further to the disease burden [15]. Stroke case fatality in 18-40-year age group has been reported as $4.2 \%$ and $19.7 \%$ at 24 and 72 hours, respectively [16].

\section{Fiji and Noncommunicable Diseases}

Fiji, a multiethnic, upper middle income [17] country with GDP of US $\$ 4,600$ and a population of 837,271 [18] lies in the South Western Pacific region. Stroke and ischaemic heart disease are the leading causes of premature disability and death [19]. Over $50 \%$ of deaths were attributed to NCDs in a survey in 1980 which rose to $82 \%$ in 2000 with stroke and coronary heart disease accounting for just over 30\% of all deaths in the 40-59-year age group [20]. WHO had projected that if the current world trends in NCDs continue, they would, by 2020 , probably account for $73 \%$ of deaths and $60 \%$ of the total world disease burden. This had already been surpassed in Fiji in 2004 [21], that is, nineteen years earlier then the WHO prediction! Recent report indicates $82 \%$ deaths in Fiji attributed to NCDs [22] with the economic impact beyond the costs to health services and increased governmental financial allocation for prevention programs [23]. There is high prevalence of chronic disability in Fiji, largely preventable diseases in persons of working age and among the young old (60-74 years) [24], a rising incidence of stroke [25], a high prevalence of comorbidities [26], and the trend towards an earlier onset of disability evident in Fiji's population [27]. The average age at which people develop diabetes and cardiovascular disease is getting lower. In Fiji, due to premature deaths only $16 \%$ of the population is aged more than 55 years [28]. The projections suggest that the incidence of stroke will rapidly increase in the near future [29]. The reported top ten stroke risk factors are probably very similar in Fiji [30]. The provision of acute care and rehabilitative services for stroke survivors needs enhancement [31].

\section{Measures of Economic Burden of Stroke: DALYs and Dollars}

Burden of stroke studies discusses cost of resource utilisation, loss of quality of life, or loss of life (mortality). Stroke imposes substantial economic burden at both microeconomic (individual/household) and macroeconomic (societal) levels. Some $24 \%$ to $33 \%$ stroke survivors report economic difficulties with return to work ranging from $0 \%$ to $100 \%$ [32]. In Fiji, at the microeconomic level when the "only breadwinner" in the family has had a stroke the loss of financial support for the family can be devastating. Kepa and Makutu [33] noted that "premature deaths in Fiji is a great concern with the implications of poverty created from loved ones lost to noncommunicable diseases becoming a serious threat." There are numerous studies from various countries addressing economic cost of resources utilisation following stroke [34-42] including economic evaluation recommendation of identification, measurement, and valuation, and then comparison of the costs (inputs) and benefits (outcomes) of two or more alternative treatments or activities $[43,44]$. A review reported the average costs of stroke ranged from US $\$ 468$ to US $\$ 146,146$ [45].

A measure for quality of life presented as estimated quality-adjusted life years (QALYs) saved or disabilityadjusted life years (DALYs) [46]. One DALY is one year of "healthy" life lost, and the burden of disease is a measurement of the gap between the current health of the population and an ideal situation in which everyone in the population lives to old age in full health [47]. In Australia, the first burden of disease and injury study using DALYs carried out using World Bank and WHO Global Burden of Disease Study methodology revealed that stroke and ischaemic heart disease were the leading causes of the total disease burden together accounting for nearly $18 \%$ of the total disease burden [19]. The available literature on the economic analysis of stroke largely deals with economic cost of care and/or resource utilisation following stroke or is expressed as disease burden as disability-adjusted life years (DALYs). The total economic burden of stroke in Fiji would include cost of resource utilisation, direct health care costs, indirect health and other costs, intangible costs, cost of carer, carers' productivity losses, and stroke survivors' productivity losses due to stroke morbidity and mortality.

\section{Human Capital}

Human capital is main value of modern society and basic factor of economic achievements and refers to the stock of skills and knowledge embodied in the ability to perform labour so as to produce economic value. Such stock valuable knowhow embodied in the labour force can be seen as surprisingly analogous to physical capital such as machines and buildings [48]. Human capital typically requires investment to be created in form of education and training, it has a market value, and it can depreciate with time [48]. In a society which places a strong emphasis on competition, financial return and viability, the "people issues" can sometimes be neglected. The theory of the human capital has appeared as a result of the application of principles of the economic theory to problems of economy of public health services, derivation, bionomics, and migration [49]. Stockley described the term human capital as recognition that people in organisations and businesses are important and essential assets who contribute to development and growth, in a similar way as physical assets such as machines and money, and that the collective attitudes, skills, and abilities of people contribute to national performance and productivity [50].

\section{Method}

This study performed an economic analysis of stroke mortality in terms of annual national human capital resource 
loss from premature deaths of young working age group in Fiji. The official retirement age is 55 years in Fiji. The loss from stroke mortality was calculated using the annual stroke mortality data obtained from Fiji Ministry of Health [51]. In Fiji stroke diagnosis is largely clinical, and the Ministry of Health mortality data used in this study is based on the clinicians' record on the death certificates. All stroke mortality aged 15-55 years was included in the analysis. An estimation of economic burden of stroke in terms of national human capital loss with some degree of accuracy can be made. There were 273 stroke deaths during the year of which 147 met the inclusion criteria being between ages of 15-55 years.

The costs of human capital resource loss may include income foregone following stroke, cost of training, recruitment and replacement of labour force, increased medical and health care costs, costs of recruiting carer(s), and loss of family carers' financial income. The loss to the economy arising from stroke of a productive worker is given by the discounted value of the output foregone over the period in which the worker is not able to earn an income, which will include period starting immediately from the onset of stroke to return to work or death. A discount rate of eight percent (8\%) was utilized to compute the present value. The maximum replacement period could be the remaining working lifespan, which is estimated by subtracting the age of the individual at stroke from the retirement age. The annual income foregone multiplied by the number of work years lost will yield the total income foregone which must be discounted using a suitable discount rate. This, of course, assumes that the individual's annual income remains the same throughout the remaining working period.

Due to varying levels of income for individuals, the average annual income is proxied by the per-capita income. The present discounted value is the value of money today (in the present) of a payment that is or was promised to be made in the future or in the past. A formula to compute the present discounted value $(\mathrm{PV})$ of the income foregone is as follows:

$$
\text { Output Loss from the Economy }=S\left(\frac{1}{r}\right)\left[1-\frac{1}{(1+r)^{t}}\right] \text {, }
$$

where, $S$ is the annual income foregone, $r$ is the chosen rate of discount, and $t$ is the working lifespan lost as the result of stroke.

The friction-cost method has been put forward as an alternative to the human-capital method as it allows more realistic estimates of productivity costs to be calculated for use in economic evaluations. The possibility of replacement of absentees is at the heart of the friction-cost method. It recognises that society will restore initial production levels after some period of adaptation, the length of which may depend on the availability of labour and, hence, on unemployment rate, which was $7.6 \%$ for Fiji. The friction-cost method has received two main criticisms in the literature: (i) it has no theoretical underpinning, and (ii) it treats leisure time as having no value. Brouwer and Koopmanschap [52] demonstrated in a "theoretical" time-allocation model how time use shifts in the friction-cost method, and that leisure is not treated as having no value. Rather, it is considered to be valued in terms of QALYs as is normally the case in economic evaluation. The time-allocation model also demonstrates that when using the friction-cost or human-capital method the changes in the amount of unpaid work and leisure time need to be valued separately. These changes should be incorporated into economic analyses.

Another approach, which can be applied to evaluate resource utilization with ranking option of intervention, is the model of resource utilization, costs, and outcome for stroke (MORUCOS) [53]. In the trial with the application of this methodology aspirin, a low-cost intervention applicable to a large number of stroke patients was evaluated against recombinant tissue-type plasminogen activator (rtPA). Analysis of health benefits, in terms of dollars and DALYs, could be produced, and the authors concluded that, if used to assess interventions across the stroke care continuum, MORUCOS offers enormous capacity to support decision making in the prioritising of stroke services. Further validation of the methodology suggests that MORUCOS is transparent and flexible in describing Australian stroke care and can effectively be used to systematically evaluate a range of different interventions even adjusting to account for stroke subtypes [54].

According to the WHO comprehensive guide to identifying the economic consequences of disease, and injury document this analysis is "Full-income models" approach which estimates value of statistical life (VSL) to years lost to disease which goes beyond purely market-based losses and as stated represents only partial estimates [55]. In this study, we use the human capital loss method as opposed to "Frictional Cost" method. In the frictional cost method, it is assumed that the worker is replaced at a later date. However, with the stroke victims' death, the worker is taken to be totally out of the economic system. Thus, the Human Capital Loss method is more appropriate. This study utilized the formula, discussed above, to compute the present value (PV) of the income foregone from stroke mortality in Fiji.

\section{Result}

Utilizing the latest available stroke mortality data obtained from Fiji Ministry of Health and a per capita National Income figure of $F \$ 5,131.50$ (US\$3,078.90) for the same year, with a discounted rate of $8 \%$, the total output loss for the economy was calculated. There were 147 young stroke deaths of working-age group comprising $53.8 \%$ of all stroke mortality. As presented in Table 1, the annual national human capital loss from stroke mortality of young workingage persons for Fiji was calculated to be $\mathrm{F} \$ 8.85$ million (US\$5.31 million).

Amongst the stroke deaths 50\% were 1-14 years and the other 50\% 15-40 years to retirement age. Figure 1 shows that the highest percentage loss from stroke mortality was from persons in their early and midforties; that is, they still had more then 10 years to retirement age of 55 years in Fiji. 
TABLE 1: Net present value of output loss from stroke mortality.

\begin{tabular}{lccccc}
\hline Number died & Years to retirement & Discounted value of output loss per person & \multicolumn{2}{c}{ Total loss } \\
\hline 3 & & $\mathrm{~F} \$ 000$ & US $\$ 000$ & $\mathrm{~F} \$ 000$ & US $\$ 000$ \\
2 & 40 & 140.4 & 84.2 & 421.2 & 252.7 \\
9 & 35 & 117.7 & 70.6 & 235.4 & 141.2 \\
13 & 30 & 114.9 & 68.9 & $1,034.1$ & 620.5 \\
16 & 100.2 & 60.1 & $1,302.6$ & 781.6 \\
30 & 25 & 83.9 & 50.3 & $1,342.4$ & 805.4 \\
34 & 15 & 65.9 & 39.5 & $1,977.0$ & 1186.2 \\
40 & 10 & 46.1 & 27.7 & $1,567.4$ & 940.4 \\
\hline Total & 5 & 24.2 & 14.5 & 968.0 & 580.8 \\
\hline
\end{tabular}

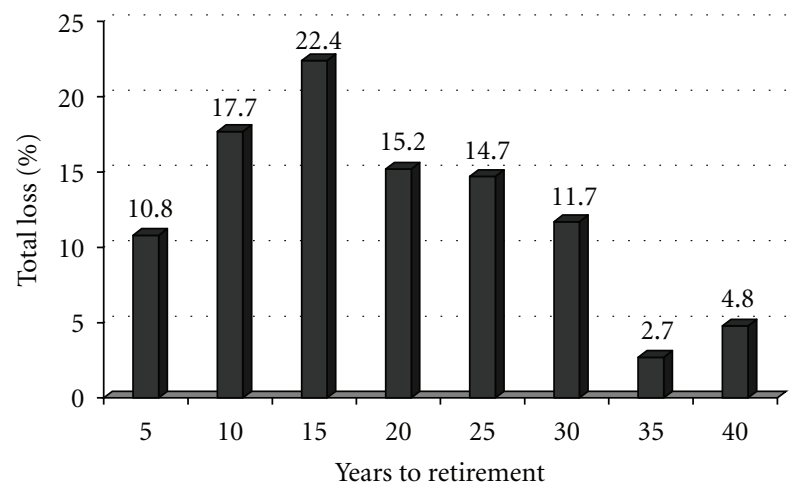

Figure 1: Years to retirement and percentage of total output loss from stroke mortality.

\section{Discussion}

The calculated national human capital resource loss from young stroke mortality for Fiji of $F \$ 8.85$ million (US\$5.31 million) is comparatively one percent of the national government revenue of F\$895.99 million (US\$537.59 million) [56] and almost ten percent (9.7\%) of the Ministry of Health's total budget of $\$ 91.02$ million (US\$54.61 million) [57] for the year. In this context, it is a substantial loss to Fiji's economy. Although it is recognised that productivity losses may begin immediately following stroke, this paper specifically and only addressed the issue of human capital loss following young stroke mortality of working-age young adults. It is important to note that the loss is a direct function of the number of working-age people who died from stroke. Therefore, if there is an increase in the incidence of stroke and mortality, this figure will also increase, thus raising the national economic loss.

This national human capital loss calculation used 55 years as the retirement age in Fiji. However, many people may remain gainfully employed past the age of 55 years in formal paid employment or informal unpaid work, caring and supporting their families [58]. Stroke incidence (and associated mortality) in Fiji has been projected to rapidly increase with increasing age $[29,59]$. Thus, if stroke mortality for ages above 55 years of age for those making an economic contribution at both micro- and macroeconomic levels is factored into the equation, the actual national human capital loss could be much higher from stroke mortality in Fiji.

In 2002, the estimated DALY's losts to stroke in Fiji was 1,442 which represented $7.1 \%$ of the total loss $(20,234$ DALY's) from all causes in Fiji [60]. Tenfold difference in rates of stroke mortality and DALY loss between the mostaffected and the least-affected countries has been reported with rates of stroke mortality and DALY loss being highest in eastern Europe, north Asia, central Africa, and the south Pacific [61]. The national per capita income, used in this study for the calculation of the national human capital resource loss happens to be the strongest predictor of mortality and DALY loss, rates $(P<0.0001)$ even after adjustment for cardiovascular risk factors $(P<0.0001)$ [61].

Apart from primary prevention of stroke, it is also very important to provide good acute medical care to prevent complications and mortality from stroke as well as providing adequate rehabilitative measures to return capable stroke survivors to productive living in the community. Improved acute care and rehabilitation will reduce the economic burden of stroke-particularly which relates to medical complications and premature mortality. It is evident that admission to hospital [62], organised acute stroke care [63-65] preferably in a specialist multidisciplinary stroke unit has better outcome both in terms of immediate survival and long-term functional outcome after rehabilitation.

There was no similar study on national human capital resource loss from stroke mortality found in the literature. However, Evers et al. [66] conducted a literature search from January 1966 to July 2003. They systematically reviewed 25 stroke cost studies and reported that the proportion of national health care budget for stroke in the eight countries studied was unequivocal for the more recent studies and was approximately $3 \%$ of total health care expenditures. In this context, Fiji's loss of an equivalent of $9.7 \%$ of health care budget due to young stroke mortality alone, not taking into account the "health care expenditures on stroke," is comparatively much higher than the reported $3 \%$.

This study specifically evaluated one aspect of economic burden of stroke in Fiji. A comprehensive study of economic 
burden of stroke, including resource utilisation, direct health care costs, indirect carer costs, intangible costs, carers productivity losses, and stroke survivors productivity losses due to stroke morbidity, was beyond the scope of this study. To calculate stroke survivors productivity losses due to stroke morbidity one needs to have data and take into account as to how long a stroke survivor gave up employment as a result of their stroke and whether the stroke survivors returned to productive work, at what level and for how long after the stroke.

\section{Conclusion}

Although this study provides only one important aspect of the economic burden of stroke in Fiji, it demonstrates that the economic loss from young working-age stroke mortality can be substantial and is not well reported in literature. This methodology can be utilized to give a fairly accurate view of economic burden not only from stroke mortality but other causes of premature mortality such as coronary artery disease, trauma, and other causes. The economic burden from premature deaths in Fiji has been raised as a growing concern to families and health workers [33]. There is lack of data on economic burden of stroke in Fiji; thus, there is opportunity for further research to evaluate many different aspects of economic burden of stroke in Fiji.

\section{References}

[1] R. Bonita and R. Beaglehole, "Stroke prevention in poor countries: time for action," Stroke, vol. 38, no. 11, pp. 2871-2872, 2007.

[2] A. Sen, Non-Communicable Diseases and Achieving the Millennium Development Goals, Health and Development Section, Emerging Social Issues Division, UNESCAP, Health and Development Series, Bangkok, Thailand, August 2006, http:// www.unescap.org/esid/hds/issues/NCD-MDG.pdf.

[3] R. Beaglehole, R. Bonita, G. Alleyne et al., "UN High-Level Meeting on Non-Communicable Diseases: addressing four questions," The Lancet, vol. 378, no. 9789, pp. 449-455, 2011.

[4] R. Bonita, "Epidemiology of stroke," The Lancet, vol. 339, no. 8789, pp. 342-344, 1992.

[5] N. V. Ramani, P. H. Kwek, and M. J. Dass, "Stroke," in Geriatric Medicine for Singapore, C. K. Ming, Y. K. Bee, and W. S. Fun, Eds., pp. 123-139, Armour, Singapore, 1996.

[6] M. E. Brandstater, "Stroke rehabilitation," in Physical Medicine and Rehabilitation: Principles and Practice, J. A. DeLisa, Ed., pp. 1656-1676, Lippincott Williams \& Wilkins, Philadelphia, Pa, USA, 2005.

[7] E. Shahar, P. G. McGovern, J. M. Sprafka et al., "Improved survival of stroke patients during the 1980s: the Minnesota stroke survey," Stroke, vol. 26, no. 1, pp. 1-6, 1995.

[8] N. E. Mayo, D. Neville, S. Kirkland et al., "Hospitalization and case-fatality rates for stroke in Canada from 1982 through 1991: the Canadian Collaborative Study Group of Stroke Hospitalizations," Stroke, vol. 27, no. 7, pp. 1215-1220, 1996.

[9] Heart and Stroke Foundation of Canada, The Changing Face of Heart Disease and Stroke in Canada, Heart and Stroke Foundation of Canada, Ottawa, Canada, 1999.
[10] D. Griffiths and J. Sturm, "Epidemiology and etiology of young stroke," Stroke Research and Treatment, vol. 2011, Article ID 209370, 9 pages, 2011.

[11] C. Marini, T. Russo, and G. Felzani, "Incidence of stroke in young adults: a review," Stroke Research and Treatment, vol. 2011, Article ID 535672, 5 pages, 2011.

[12] A. S. Kim and S. C. Johnston, "Global variation in the relative burden of stroke and ischemic heart disease," Circulation, vol. 124, no. 3, pp. 314-323, 2011.

[13] V. L. Feigin, C. M. Lawes, D. A. Bennett, S. L. Barker-Collo, and V. Parag, "Worldwide stroke incidence and early case fatality reported in 56 population-based studies: a systematic review," The Lancet Neurology, vol. 8, no. 4, pp. 355-369, 2009.

[14] World Health Organisation, "NCD Surveillance: STEPwise approach to stroke surveillance," February 2006, http://www .who.int/ncd_surveillance/steps/stroke/en/.

[15] M. Tripathi and D. Vibha, "Stroke in young in India," Stroke Research and Treatment, vol. 2011, Article ID 368629, 6 pages, 2011.

[16] L. F. Owolabi and A. Ibrahim, "Stroke in young adults: a prospective study from Northwestern Nigeria," International Scholarly Research Network Neurology, vol. 2012, Article ID 468706, 5 pages, 2012.

[17] World Bank, "How we classify countries," 2012, http://data .worldbank.org/about/country-classifications.

[18] Wikipedia, "Demographics of Fiji," 2012, http://en.wikipedia .org/wiki/Demographics_of_Fiji\#2007_Census.

[19] C. D. Mathers, E. T. Vos, C. E. Stevenson, and S. J. Begg, "The Australian burden of disease study: measuring the loss of health from diseases, injuries and risk factors," Medical Journal of Australia, vol. 172, no. 12, pp. 592-596, 2000.

[20] Fiji Islands Ministry of Health, 2003 Annual Report. Parliamentary Paper No. 45 of 2005, Ministry of Health, Suva, Fiji, 2003.

[21] Fiji Islands Ministry of Health, 2004 Annual Report. Parliamentary Paper No. 123 of 2005, Ministry of Health, Suva, Fiji, 2004.

[22] G. Waqa, “NCDs Blamed for Deaths," Fiji Times, March 2010, http://www.fijitimes.com.fj/story.aspx?id=141852.

[23] F. Waqabaca, "NCDs Threat," Fiji Times, April 2011, http:// www.fijitimes.com/story.aspx?id=170166.

[24] M. Price, Care for the Elderly Report, Ministry of Health, Suva, Fiji, 1997.

[25] J. C. Maharaj, "Policy and programme for health care of older persons," in Proceedings of the 41st Fiji Medical Association Annual Conference-Health care of Older Persons: Ageing o Health into the New Millennium, Suva, Fiji, September 1999.

[26] J. C. Maharaj and F. Ehrlich, "Elderly persons admitted to general medical wards in Fiji," BOLD Quarterly Journal of the International Institute on Ageing, vol. 10, no. 1, pp. 17-26, 1999.

[27] S. V. Panapasa, "Disability among older women and men in Fiji: concerns for the future," Journal of Women and Aging, vol. 14, no. 1-2, pp. 149-162, 2002.

[28] World Health Organisation, "Programmes and projects," Bulletin of the World Health Organization, vol. 88, no. 7, pp. 481-560, 2010.

[29] J. C. Maharaj and S. V. Panapasa, "Burden of stroke among Fiji's older persons," in Proceedings of the International Union of Scientific Study of Population (IUSSP '02), Bangkok, Thailand, June 2002, http://www.iussp.org/Bangkok2002/S7Maharaj.pdf. 
[30] M. J. O’Donnell, X. Denis, L. Liu et al., "Risk factors for ischaemic and intracerebral haemorrhagic stroke in 22 countries (the INTERSTROKE study): a case-control study," The Lancet, vol. 376, no. 9735, pp. 112-123, 2010.

[31] M. Lowe, "Hypertension and stroke," in Health and Disease in Fiji, M. Lowe, Ed., School of Medicine, Suva, Fiji, 1st edition, 2001.

[32] K. Daniel, C. D. A. Wolfe, M. A. Busch, and C. Mckevitt, "What are the social consequences of stroke for working-aged adults?: a systematic review," Stroke, vol. 40, no. 6, pp. e431-e440, 2009.

[33] M. Kepa and B. Makutu, "Nurses as actors in health promotion," July 2008, http://www.samoanursing.ws/abstract $\% 20$ .html.

[34] T. N. Taylor, P. H. Davis, J. C. Torner, J. Holmes, J. W. Meyer, and M. F. Jacobson, "Lifetime cost of stroke in the United States," Stroke, vol. 27, no. 9, pp. 1459-1466, 1996.

[35] R. L. Sacco, E. J. Benjamin, J. P. Broderick et al., "Risk factors: public health burden of stroke," Stroke, vol. 28, pp. 1507-1517, 1997.

[36] L. B. Morgenstern, "Outcomes in stroke: reducing the economic burden,” 2006, http://www.plavix.com/stroke.aspx.

[37] H. M. Dewey, A. G. Thrift, C. Mihalopoulos et al., "Lifetime cost of stroke subtypes in Australia: findings from the North East Melbourne Stroke Incidence Study (NEMESIS)," Stroke, vol. 34, no. 10, pp. 2502-2507, 2003.

[38] H. M. Dewey, A. G. Thrift, C. Mihalopoulos et al., "Cost of stroke in Australia from a societal perspective: results from the North East Melbourne Stroke Incidence Study (NEMESIS)," Stroke, vol. 32, no. 10, pp. 2409-2416, 2001.

[39] H. S. Jørgensen, H. Nakayama, H. O. Raaschou, and T. S. Olsen, "Acute stroke care and rehabilitation: an analysis of the direct cost and its clinical and social determinants. The Copenhagen Stroke Study," Stroke, vol. 28, no. 6, pp. 1138-1141, 1997.

[40] S. Gerzeli, R. Tarricone, P. Zolo, I. Colangelo, M. R. Busca, and C. Gandolfo, "The economic burden of stroke in Italy. The EcLIPSE study: economic longitudinal incidence-based project for stroke evaluation," Neurological Sciences, vol. 26, no. 2, pp. 72-80, 2005.

[41] A. Terent, L. A. Marke, K. Asplund, B. Norrving, E. Jonsson, and P. O. Wester, "Costs of stroke in Sweden: a national perspective," Stroke, vol. 25, no. 12, pp. 2363-2369, 1994.

[42] S. M. A. A. Evers, A. J. H. A. Ament, and G. Blaauw, "Economic evaluation in stroke research: a systematic review," Stroke, vol. 31, no. 5, pp. 1046-1053, 2000.

[43] M. F. Drummond, B. O'Brien, G. L. Stoddart, and G. W. Torrance, Methods for Economic Evaluation of Health Care Programmes, Oxford University Press, Oxford, UK, 1997.

[44] World Health Organization, "Workbook 8: economic evaluations-evaluation of psychoactive substance use disorder treatment," WHO/MSD/MSB 00.2i, November 2008, http:// www.unodc.org/docs/treatment/economic_evaluation.pdf.

[45] R. Luengo-Fernandez, A. M. Gray, and P. M. Rothwell, "Costs of stroke using patient-level data: a critical review of the literature.," Stroke, vol. 40, no. 2, pp. e18-23, 2009.

[46] C. J. Murray and A. D. Lopez, The Global Burden of Disease: A Comprehensive Assessment of Mortality and Disability from Diseases, Injuries and Risk Factors in 1990 and Projected to 2020, vol. 1 of Global Burden of Disease and Injury Series, Harvard School of Public Health, Harvard, UK, 1996.

[47] K. Strong, C. Mathers, and R. Bonita, "Preventing stroke: saving lives around the world," The Lancet Neurology, vol. 6, no. 2, pp. 182-187, 2007.

[48] B. Graham, E. Davis, P. Trott, and M. Uncles, The New Penguin Dictionary of Business, Penguin Books, London, UK, 2002.
[49] O. Pushkarev, "Method and criterion of an estimation of the human capital," KORUS, Life Science, Biotehnology, Medicine, vol. 4, pp. 65-68, 2003.

[50] D. Stockley, "Human capital concept-definition and explanation," September 2008, http://derekstockley.com.au/newsletters-05/018-human-capital.html.

[51] Fiji Islands Ministry of Health, Stroke Mortality in Fiji [I64] 1998-2001, Ministry of Health, Suva, Fiji, 2005.

[52] W. B. F. Brouwer and M. A. Koopmanschap, "The frictioncost method: replacement for nothing and leisure for free?" PharmacoEconomics, vol. 23, no. 2, pp. 105-111, 2005.

[53] M. L. Moodie, R. Carter, C. Mihalopoulos et al., "Trial application of a Model of Resource Utilization, Costs, and Outcomes for Stroke (MORUCOS) to assist priority setting in stroke," Stroke, vol. 35, no. 5, pp. 1041-1046, 2004.

[54] C. Mihalopoulos, D. A. Cadilhac, M. L. Moodie et al., "Development and application of Model of Resource Utilization, Costs, and Outcomes for Stroke (MORUCOS): an Australian economic model for stroke," International Journal of Technology Assessment in Health Care, vol. 21, no. 4, pp. 499-505, 2005.

[55] World Health Organisation, "Guide to identifying the economic consequences of disease and injury," 2009, http:// www.who.int/choice/publications/d_economic_impact_guide .pdf.

[56] Fiji Islands Revenue and Customs Authority, "Annual Report 2005," http://www.frca.org.fj/docs/firca/legislations_regulations/firca_annual\%20_report_2005.pdf.

[57] Fiji Islands Ministry of Health, "2001 Annual Report," Parliamentary Paper No. 43 of 2005, Ministry of Health, Suva, Fiji, 2005.

[58] J. Siegrist, O. V. D. Knesebeck, and C. E. Pollack, "Social productivity and well-being of older people: a sociological explanation," Social Theory and Health, vol. 2, pp. 1-17, 2004.

[59] J. C. Maharaj and N. Venketasubramanian, "Burden of stroke in Fiji," International Journal of Stroke, vol. 5, no. 4, pp. 321$322,2010$.

[60] World Health Organisation, "Death and disability-adjusted life years (DALYs) estimates for 2002 by cause for WHO Member," July 2008, http://www.who.int/healthinfo/global_ burden_disease/estimates_country/en/index.html.

[61] S. C. Johnston, S. Mendis, and C. D. Mathers, "Global variation in stroke burden and mortality: estimates from monitoring, surveillance, and modelling," The Lancet Neurology, vol. 8, no. 4, pp. 345-354, 2009.

[62] P. L. Henneman and R. J. Lewis, "Is admission medically justified for all patients with acute stroke or transient ischemic attack?" Annals of Emergency Medicine, vol. 25, no. 4, pp. 458463, 1995.

[63] M. Naylor, D. Brooten, R. Jones, R. Lavizzo-Mourey, M. Mezey, and M. Pauly, "Comprehensive discharge planning for the hospitalized elderly: a randomized clinical trial," Annals of Internal Medicine, vol. 120, no. 12, pp. 999-1006, 1994.

[64] A. Jones, E. K. Carr, D. J. Newham, and J. Wilson-Barnett, "Positioning of stroke patients: evaluation of a teaching intervention with nurses," Stroke, vol. 29, no. 8, pp. 1612-1617, 1998.

[65] Stroke Unit Trialists' Collaboration, “Organised inpatient (stroke unit) care for stroke," Cochrane Database Systemic Review, vol. 1, Article ID CD000197, 2002.

[66] S. M. A. A. Evers, J. N. Struijs, A. J. H. A. Ament, M. L. L. Van Genugten, J. C. Jager, and G. A. M. Van Den Bos, "International comparison of stroke cost studies," Stroke, vol. 35, no. 5, pp. 1209-1215, 2004. 


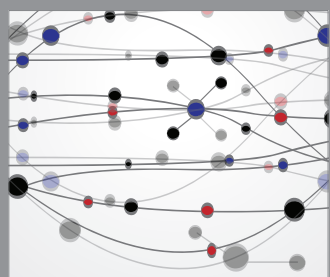

The Scientific World Journal
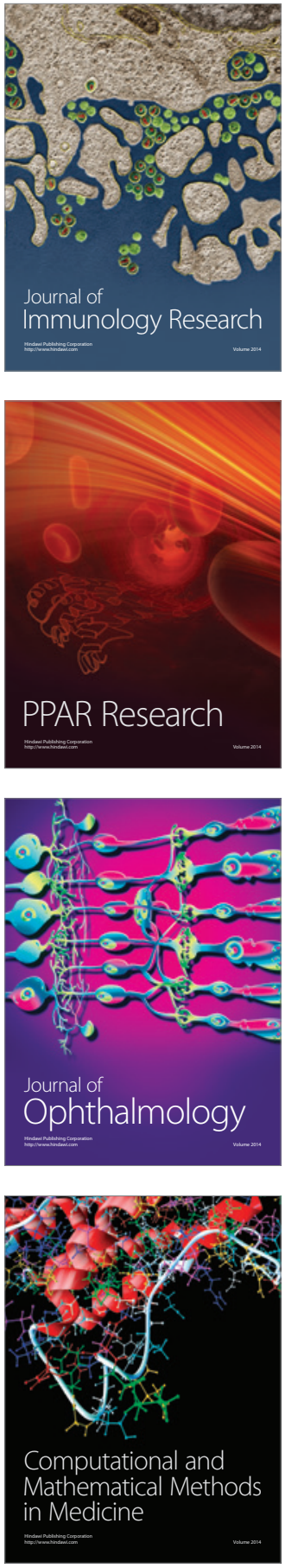

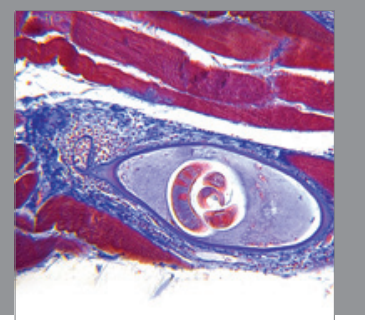

Gastroenterology

Research and Practice
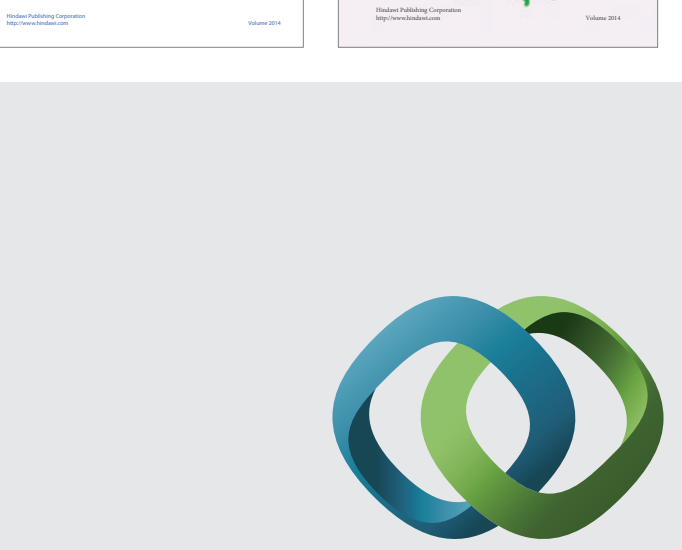

\section{Hindawi}

Submit your manuscripts at

http://www.hindawi.com
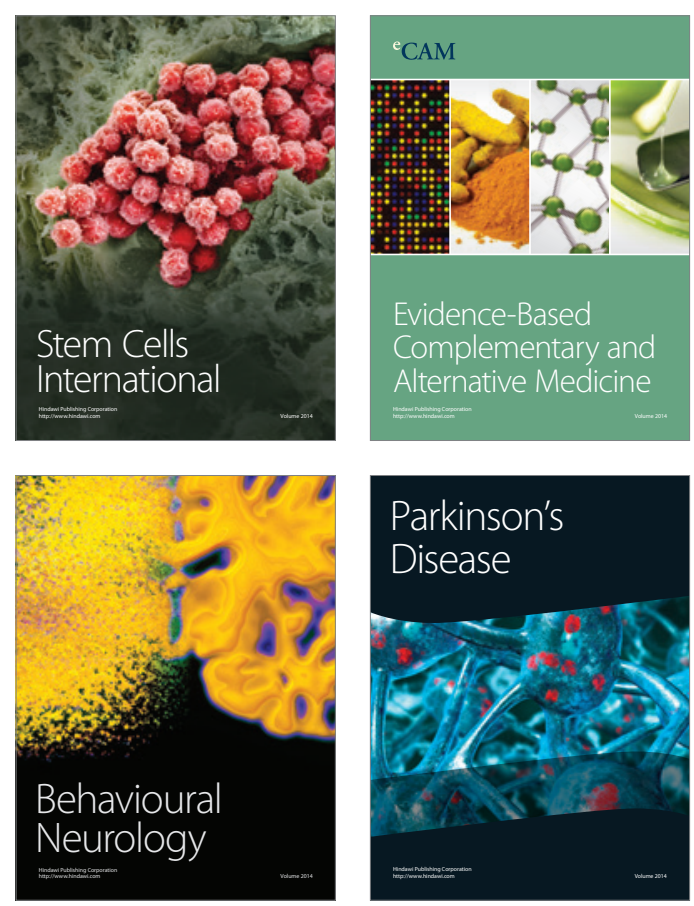

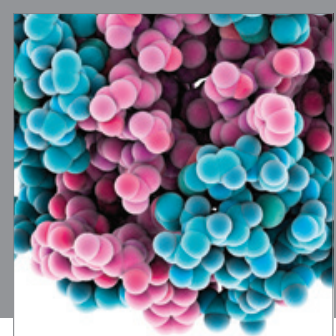

Journal of
Diabetes Research

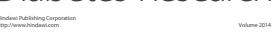

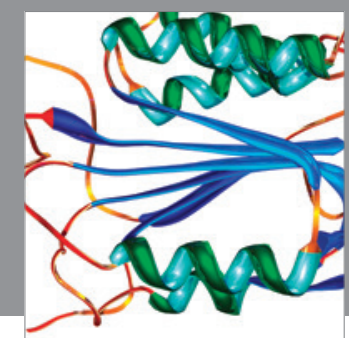

Disease Markers
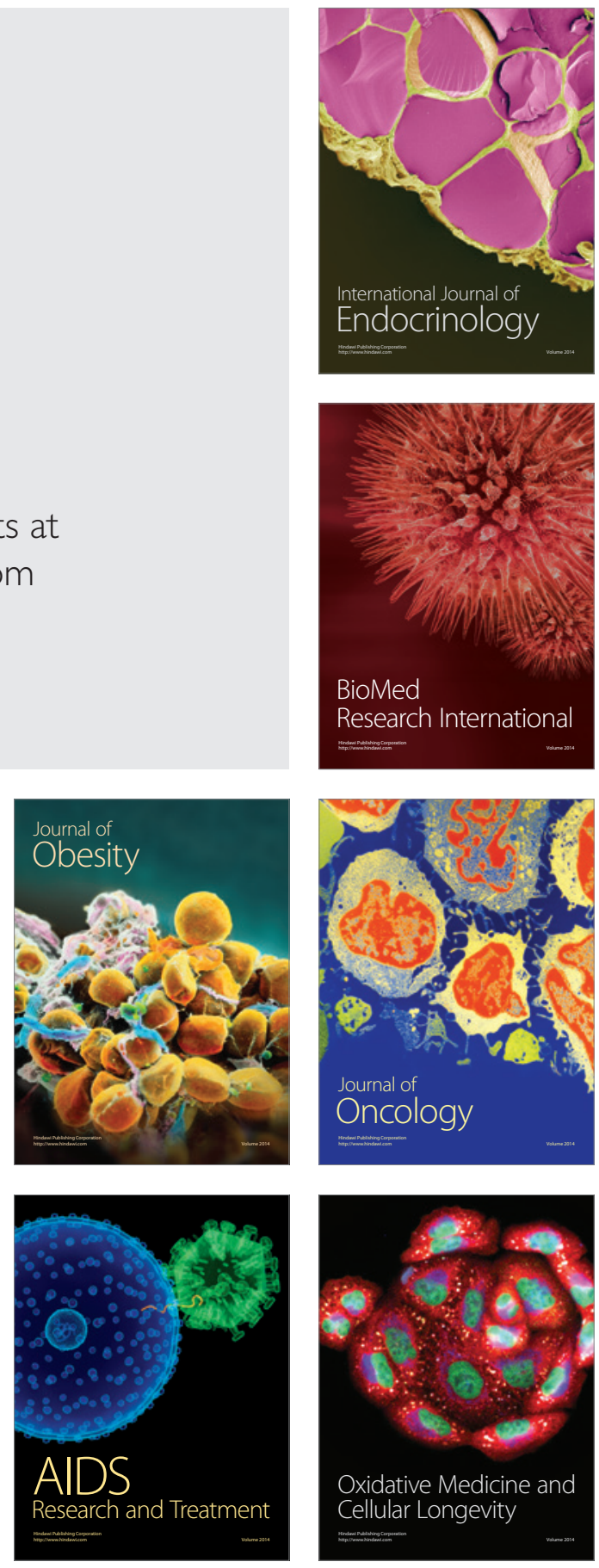